\title{
Influences of Environmental Perception on Individual Cognitive Engagement in Online Learning: The Mediating Effect of Self-Efficacy
}

\author{
https://doi.org/10.3991/ijet.v17i04.29221 \\ Lei Liu ${ }^{1}$, Zhaolin Duan ${ }^{2}(\varpi)$ \\ ${ }^{1}$ Wuhan Textile University, Wuhan, China \\ ${ }^{2}$ Wuhan University of Technology, Wuhan, China \\ dzl@whut.edu.cn
}

\begin{abstract}
During online learning, complicated environmental perception factors influence the cognitive engagement of students, which is an influencing variable of learning motivation, learning outcomes, and other classroom effect indicators. In this study, the research hypotheses on the influences of the environmental perception of online learning (including students' self-factors, teacher factors, peer factors, and technological factors) on individual cognitive engagement (deep engagement and superficial engagement) were proposed. The mediating effect of the influences of self-efficacy on individual cognitive engagement under the online learning model was estimated. Results demonstrate that the Cronbach's $\alpha$ of the questionnaire used in the study is 0.891 and the $\mathrm{KMO}$ is 0.841 . These outcomes reflect that this questionnaire has very good reliability and validity. In the online learning environment, students' self-factors, peer factors, and technological factors can promote individual cognitive engagement significantly. Furthermore, self-efficacy develops a mediating effect in the significantly positive promotion of environmental perception on individual cognitive engagement. Cognitive engagement also changes with the duration of online learning $(\mathrm{F}=4.530, p=0.005)$. Moreover, the influences of majors on cognitive engagement are significant at the 0.05 level $(\mathrm{F}=2.188, p=0.047)$. Conclusions have important references to comprehend the influences of different environmental perception factors on individual cognitive engagement in the process of online learning and disclose how self-efficacy influences individual cognitive engagement.
\end{abstract}

Keywords —online learning, environmental perception, self-efficacy, cognitive engagement, mediating effect

\section{$1 \quad$ Introduction}

The latest developments in information technology (IT), such as 5G technology, information technology, and artificial intelligence (AI), will revolutionize the education industry, which will further promote the follow-up of education behaviors and thereby realize leapfrog development. The teaching environment has evolved from 
traditional classrooms and electronic whiteboards to IT tools centered at various digital terminals, AI, big data, cloud computation, and other technologies. This evolution brings a great challenge to the traditional education philosophy of teachers. Education is not education in the traditional sense anymore, and learning is not learning in the traditional sense. The connotations have been changed unconsciously, accompanied by changes in extensions. Online learning has been extensively implemented worldwide. In particular, studies on education informationization have reached a profound research level, and all schools need to accept and adapt to a series of changes brought by online learning to keep up with the times. Under this notion, China has the biggest population of online education in the world, and it has large-scale curriculum resource development and curriculum applications. In such background, online learning quality must be improved urgently to realize the sustainable development of online learning. Now, China's education is fully student-oriented and mainly adopts the teacherstudent interaction to motivate the learning enthusiasm and endogenous power of students and develop the talent training-oriented teaching mode. The development degree of learning proactivity and expected learning outcome of students can be investigated more comprehensively by focusing on their learning engagement. Numerous scholars in education studies have been highly concerned with and have investigated the concept of learning engagement, which is introduced from the perspective of positive psychology. Scholars have proven through different tool methods and research objects that learning engagement has a high prediction effect on the learning outcomes of students.

Several existing studies have demonstrated that cognitive engagement is positively related to the academic achievement of learners. Cognitive engagement is a process in which learners build knowledge systems and acquire knowledge results by using learning measures and appropriate learning strategies positively. It also involves the ability of learners to adjust their learning behaviors according to learning outcomes. Teacher feedback is an important factor that trains and promotes the cognitive engagement of learners. Without timely teacher feedback, learners will have difficulty recognizing their poor learning outcomes and have slow progress in learning. Reminding learners about important affairs or details that they might have missed during the learning proper and providing them information about their learning conditions can help learners in the real-time monitoring and regulation of learning activities and guide them to learn to evaluate the scientificity of their learning methods and validity of learning outcomes. As a result, such feedback promotes students' metacognition development. To assure substantial equivalence between online learning quality and offline learning quality, learners must be equipped with high cognitive engagement. The online learning mode allows for a smoother transition for learners when transferring from the existing offline group learning environment to the relatively separated individual online learning environment. However, such social isolation caused by online teaching technology brings some difficulties for learners in devoting themselves to learning activities. Hence, the low cognitive engagement of learners in the online learning environment has become a universal phenomenon. The cognitive engagement has attracted much academic attention, as it reflects the high-order engagement of learners in learning activities. However, deep analyses on cognitive en- 
gagement have rarely been conducted. Therefore, exploring effective cognitive engagement strategies in online learning and promoting the cognitive engagement of online learners are important guarantees to popularize online education and realize the sustainable development of online education in the future.

\section{Theoretical background and hypothesis development}

Bandura [1] believed in social cognitive theory, which explains that individuals, as the major executor of learning, are easily influenced by the interaction between their feelings and their surrounding environment. This theory is also the theoretical basis for studying education cognition and relevant influencing factors in this study. In social cognitive theory, the framework of "individual-environment-behavior" mutual influences is proposed, and a theoretical study on self-efficacy is carried out. The mutual influences of "individual-environment-behavior" emphasize that people, behavior, and environment can form mutual causalities and any two factors can produce mutual influencing relations that have complicated changes. It presents one-way or two-way relations of mutual promotion and reciprocal causation. On the basis of social cognitive theory, this study argues that the individual factor refers to the selfefficacy of learners and the environmental factor refers to the environmental perception of online learning. Environmental perception can be interpreted from multiple aspects, including students' self-factors, teacher factors, peer factors, and technological factors. Cognitive engagement uses the relatively classical definition. In this study, cognitive engagement is introduced from deep cognition and superficial cognition.

As the education scene for communication between teachers and students, the online classroom environment must be based on the promotion of growth and development of students, including students' perception of classroom environment, cognition, self-concept, learning attitude, self-efficacy, and learning motivation. It is the sum of various physical, social, and psychological factors. Studies on the influences of cognitive engagement and its relations with other influencing factors have been applied and studied extensively worldwide. Appleton et al. [2] evaluated the degree of participation of students according to the responses of 1931 students in Grade 9 to city samples with diversified races and economic conditions. He concluded that the cognitive engagement of students was composed of six factors. In a later study, Smit et al. [3] examined the mediating effect of students' motivational strategy between motivational belief and motivation engagement. He carried out a questionnaire survey of 3602 students from pre-service secondary education in the Netherlands and found that environmental control, interest strengthening, self-balance, the performances of self-talk, and the mastery of self-talk have relatively strong direct relations with the motivational beliefs of students. In addition, Chi et al. [4] demonstrated that teachers' understanding of ICAP (Interactive, Constructive, Active, and Passive) and teachers' loyalty to classroom implementation after finishing online modules have highly evident influences on the cognitive engagement and learning outcomes of students. Miltiadou and Savenye [5] believed that the cognitive engagement of students and pro- 
vided six motivations for them to achieve success in online courses, including selfefficacy, control point, attributions, target orientations, internal and external motivations, and self-regulation. Songkram et al. [6] pointed out that the electronic learning system can significantly improve the cognitive skills of students. This system has two subsystems: the e-learning system in the hybrid learning environment and the elearning system in the virtual learning environment (VLF). Yi [7] pointed out that learning cognition input is one of the most direct and most lasting problems in education practices; such input is a key factor in measuring online learning quality. In addition, he built a learning analysis model for online cognitive input evaluation. Meanwhile, Lamb et al. [8] simulated the cognitive training intervention of 100,000 students using a random control test design. According to simulation results, the learning performances of learners can be improved effectively using the high-efficiency cognitive attribute method. Rotgans and Schmidt [9] discussed how cognitive engagement determines the follow-up cognitive levels with the learning process. Significant increases in the cognitive engagement of students can increase learning outcomes effectively. Helme and Clarke [10] analyzed video and interview data of four math classes for Grade 8 and found that students' cognition is influenced by the classroom scenarios, tasks, and specific aspects of individuals. Archambault et al. [11] deemed that teenagers still participate in high school life positively; however, their performances in observing rules, interests in school, and willingness to learn have declined. Research has demonstrated that creating a positive social and emotional learning environment can help teenagers to achieve better performances. Metallidou and Vlachou [12] believed that self-efficacy, intrinsic value, examination anxiety, cognitive strategy use, and self-regulation strategy are major factors that influence the cognitive engagement of students. Moreover, cognitive strategy develops an evident mediating effect in the relationship between motivation and performance. Li and Lerner [13] studied and investigated the mutual relationship between individual behaviors and individual emotions. Results demonstrated that behavior and emotional inputs are two-way and behavior is the primary influencing factor of cognitive engagement. Walker et al. [14] investigated the motivation structural identification of 191 university students. According to path analysis, self-efficacy, intrinsic motivation, and academic identity have unique contributions to the prediction of meaningful cognitive engagement. Archambault et al. [15] discussed the regulation effect of teachers' expectation and ordinary efficacy on the relationship between the academic performances of students and their cognitive engagement one year later. The results showed that the self-report belief of teachers influences the cognitive engagement and academic experiences of students.

According to the above literature review, the cognitive engagement of individuals is affected by individual factors and environmental factors. In particular, learning selfefficacy in individual factors and teaching environmental perception are important factors that influence cognitive engagement under the online learning mode. Based on the summary of the existing studies, the teaching environmental perception has been defined as four aspects of students' self-factor, teacher factor, peer factor, and technological factor. With respect to cognitive engagement, the research fruits of Greene [16] are extensively applied. He divided cognitive engagement into deep cognitive 
engagement and superficial cognitive engagement. The superficial cognitive engagement mainly includes repeated reading, memory information, and retelling memory contents. Deep cognitive engagement covers information processing and identification, the integration of new and old information, and other learning processes. Therefore, cognitive engagement is defined as two aspects of superficial cognitive engagement and deep cognitive engagement. On the basis of the above theories and analyses, some hypotheses are proposed in the present study.

- H1: In the online learning environment, students' self-factors have a significantly positive promotion effect on individual cognitive engagement.

$-\mathrm{H} 2$ : In the online learning environment, teacher factors have a significantly positive promotion effect on individual cognitive engagement.

- H3: In the online learning environment, peer factors have a significantly positive promotion effect on individual cognitive engagement.

- H4: In the online learning environment, technological factors have a significantly positive promotion effect on individual cognitive engagement.

- H5: In the online learning environment, self-efficacy develops a mediating effect in the significantly positive promotion of environmental perception on individual cognitive engagement.

\section{Methodology}

\subsection{Questionnaire design}

This study investigates how the environmental perception of university students influences cognitive engagement in the background of online learning. In addition, the influencing paths of the different aspects of environmental perception on cognitive engagement are estimated. Next, a questionnaire to investigate the influences of the environmental perception and self-efficacy of online learning on cognitive engagement is built. The questionnaire covers three aspects. The first part is the general information of respondents, including gender, duration of online learning, major, and grade. The second part includes the core problems of the questionnaire, which are redesigned by the research team according to existing studies. It covers the six variables of students' self-factors, peer factors, teacher factors, technological factors, superficial cognitive engagement, and deep cognitive engagement, which involve four, four, three, four, three, and three questions, respectively. The third part is the measurement of self-efficacy, which applies the questionnaire in the study of Greene et al. [17].

\subsection{Research objects}

In this study, undergraduates from Accounting, Human Resource Management, and other majors in the School of Economics and Management of an ordinary university in Hubei Province were selected as respondents. The university had input more 
than 20 million $\mathrm{CNY}$ to realize the full integration of 5G technology and campus network, the building of an informatization platform, and the construction of informationization. The overall online learning hardware environment had been perfected among ordinary universities in Hubei Province, and students had been able to experience online-offline hybrid learning reform since 2019. The overall online learning outcomes of students were satisfactory. Most students were very familiar with online learning and had rich experiences. Influenced by the COVID-19 pandemic, the selected university provided online learning in the first two weeks of the first semester in the academic year from 2020 to 2021. As a result, most students experienced online learning. After the return to offline teaching, the research team came to the university and sent paper questionnaires. After obtaining informed consent from course teachers and students, students were asked to fill in the questionnaire. A total of 206 questionnaires were collected. After invalid questionnaires were deleted, 157 valid ones were retained, and the recovery efficiency was $76.21 \%$.

Table 1. Descriptive statistical results

\begin{tabular}{|c|c|c|c|c|c|}
\hline $\begin{array}{l}\text { Name of } \\
\text { questions }\end{array}$ & Answers & $\begin{array}{c}\text { Answer } \\
\text { no. }\end{array}$ & $\begin{array}{l}\text { Frequency } \\
\text { number }\end{array}$ & $\begin{array}{c}\text { Percentage } \\
(\%)\end{array}$ & $\begin{array}{c}\text { Cumulative } \\
\text { percentage }(\%)\end{array}$ \\
\hline \multirow{2}{*}{ Gender } & Male & 0 & 86 & 54.78 & 54.78 \\
\hline & Female & 1 & 71 & 45.22 & 100 \\
\hline \multirow{4}{*}{$\begin{array}{l}\text { Duration of } \\
\text { online learning }\end{array}$} & $>$ Half a year & 1 & 53 & 33.76 & 33.76 \\
\hline & $0.5-1$ year & 2 & 65 & 41.4 & 75.16 \\
\hline & $1-2$ years & 3 & 18 & 11.46 & 86.62 \\
\hline & $>2$ years & 4 & 21 & 13.38 & 100 \\
\hline \multirow{7}{*}{ Majors } & Accounting & 1 & 25 & 15.92 & 15.92 \\
\hline & Human Resource Administration & 2 & 71 & 45.22 & 61.15 \\
\hline & International Economics and Trade & 3 & 29 & 18.47 & 79.62 \\
\hline & Finance & 4 & 13 & 8.28 & 87.9 \\
\hline & Statistics & 5 & 2 & 1.27 & 89.17 \\
\hline & Fiscal Science & 6 & 5 & 3.18 & 92.36 \\
\hline & MBA & 7 & 12 & 7.64 & 100 \\
\hline \multirow{4}{*}{ Grade } & Freshman & 1 & 14 & 8.92 & 8.92 \\
\hline & Sophomore year & 2 & 18 & 11.46 & 20.38 \\
\hline & Junior & 3 & 92 & 58.6 & 78.98 \\
\hline & Senior & 4 & 33 & 21.02 & 100 \\
\hline \multicolumn{2}{|l|}{ Total } & - & 157 & 100 & 100 \\
\hline
\end{tabular}

\section{$4 \quad$ Results analysis}

\subsection{Reliability and validity test}

The reliability of the questionnaire refers to the consistency, stability, and reliability of test results, and it is usually expressed by internal consistency. The higher relia- 
bility coefficient indicates the higher consistency, stability, and reliability of test results. This reliability is usually measured and expressed by Cronbach's $\alpha$.

Table 2 shows that the Cronbach's $\alpha$ of the questionnaire is 0.891 . Moreover, the Cronbach's $\alpha$ of all six variables is higher than 0.7 , thus indicating that the research data in this study have very good reliability quality.

Table 2. Reliability test results

\begin{tabular}{|c|c|c|c|c|c|}
\hline Variables & $\begin{array}{l}\text { Name of questions in } \\
\text { the questionnaire }\end{array}$ & $\begin{array}{c}\text { Correction item-total } \\
\text { correlation (CITC) }\end{array}$ & $\begin{array}{c}\alpha \text { coefficient with } \\
\text { item deleted }\end{array}$ & $\begin{array}{c}\text { Cronbac } \\
\text { h's } \alpha\end{array}$ & $\begin{array}{c}\text { Cronbach' } \\
\text { s a }\end{array}$ \\
\hline \multirow{4}{*}{$\begin{array}{l}\text { Students' self- } \\
\text { factors } \\
\text { (Factor1) }\end{array}$} & $\mathrm{A} 1$ & 0.546 & 0.672 & \multirow{4}{*}{0.739} & \multirow{21}{*}{0.891} \\
\hline & $\mathrm{A} 2$ & 0.547 & 0.671 & & \\
\hline & $\mathrm{A} 3$ & 0.536 & 0.677 & & \\
\hline & A4 & 0.501 & 0.700 & & \\
\hline \multirow{4}{*}{$\begin{array}{l}\text { Peer factors } \\
\text { (Factor2) }\end{array}$} & $\mathrm{B} 1$ & 0.408 & 0.750 & \multirow{4}{*}{0.733} & \\
\hline & B2 & 0.589 & 0.636 & & \\
\hline & B3 & 0.598 & 0.630 & & \\
\hline & B4 & 0.524 & 0.673 & & \\
\hline \multirow{3}{*}{$\begin{array}{l}\text { Teacher } \\
\text { factors } \\
\text { (Factor3) }\end{array}$} & $\mathrm{C} 1$ & 0.683 & 0.797 & \multirow{3}{*}{0.839} & \\
\hline & $\mathrm{C} 2$ & 0.708 & 0.772 & & \\
\hline & $\mathrm{C} 3$ & 0.720 & 0.760 & & \\
\hline \multirow{4}{*}{$\begin{array}{l}\text { Technological } \\
\text { factors } \\
\text { (Factor4) }\end{array}$} & D1 & 0.601 & 0.671 & \multirow{4}{*}{0.755} & \\
\hline & D2 & 0.707 & 0.604 & & \\
\hline & D3 & 0.672 & 0.629 & & \\
\hline & D4 & 0.260 & 0.833 & & \\
\hline \multirow{3}{*}{$\begin{array}{l}\text { Superficial } \\
\text { cognitive } \\
\text { engagement } \\
\text { (Factor5) }\end{array}$} & Y1-1 & 0.408 & 0.719 & \multirow{3}{*}{0.691} & \\
\hline & $\mathrm{Y} 1-2$ & 0.615 & 0.448 & & \\
\hline & Y1-3 & 0.504 & 0.600 & & \\
\hline \multirow{3}{*}{$\begin{array}{l}\text { Deep cogni- } \\
\text { tive engage- } \\
\text { ment } \\
\text { (Factor6) }\end{array}$} & Y2-1 & 0.610 & 0.870 & \multirow{3}{*}{0.841} & \\
\hline & Y2-2 & 0.775 & 0.708 & & \\
\hline & $\mathrm{Y} 2-3$ & 0.763 & 0.724 & & \\
\hline
\end{tabular}

The validity, also known as effectiveness, means that the measurement tools or means can measure the degree of the measured object accurately. Validity refers to the degree to which the measured results reflect the investigation content. If the measurement results and the investigation content agree more, the validity is higher; otherwise, the validity is lower.

In Table 3, the clinodiagonal indicates the square root of AVE, and the remaining values are correlation coefficients. The square roots of AVE of all factors are higher than the absolute value of the correlation coefficient between this factor and other factors. Moreover, this conclusion is observed in all the factors, thus indicating good discrimination validity. 
Paper-Influences of Environmental Perception on Individual Cognitive Engagement in Online Learning...

Table 3. Discrimination validity: Pearson correlation and the square root of AVE

\begin{tabular}{|l|c|c|c|c|c|c|}
\hline & Factor1 & Factor2 & Factor3 & Factor4 & Factor5 & Factor6 \\
\hline Factor1 & 0.645 & - & - & - & - & - \\
\hline Factor2 & 0.534 & 0.639 & - & - & - & - \\
\hline Factor3 & 0.503 & 0.648 & 0.795 & - & - & - \\
\hline Factor4 & 0.421 & 0.480 & 0.621 & 0.720 & - & - \\
\hline Factor5 & 0.304 & 0.118 & 0.180 & 0.429 & 0.665 & - \\
\hline Factor6 & 0.296 & 0.122 & 0.249 & 0.403 & 0.675 & 0.830 \\
\hline
\end{tabular}

Table 4 shows that the KMO value is 0.841 , which is higher than 0.8 , thus indicating that the measure is highly appropriate for information extraction. Through the Bartlett test, the corresponding $p$-value is $0.000(<0.05)$, thus indicating that the questionnaire has very good validity.

Table 4. KMO and Bartlett test

\begin{tabular}{|l|c|c|}
\hline KMO & & 0.841 \\
\cline { 2 - 3 } Bartlett Sphericity test & Approximate Chi-square & 1655.692 \\
\cline { 2 - 3 } & $\mathrm{df}$ & 210 \\
\cline { 2 - 3 } & $\mathrm{P}$ & 0 \\
\hline
\end{tabular}

\subsection{Regression analysis}

Table 5 demonstrates the following:

Hypothesis $\mathrm{H} 1$ is verified. In the environment of online learning, students' selffactors have a significantly positive promotion effect on individual cognitive engagement. This finding is consistent with the conclusions of most studies. As online learning is a result of learners' positive participation in online teaching and interaction with teachers, learners are equipped with strong learning proactivity to participate in teacher-student and student-student interactions more actively. Particularly, students with stronger self-control have stronger learning motivation. In addition, they engage more easily in problem discussions, brainstorming, after-class tests, and in-class random questioning during online learning. By participating in classroom learning, students' good learning habits and learning attitudes aid them in accomplishing online learning tasks better.

Table 5. Linear regression results

\begin{tabular}{|c|c|c|c|c|c|}
\hline Influencing factors & Normalization coefficient & $\mathbf{T}$ & $\mathbf{P}$ & VIF & $\mathbf{F}$ \\
\hline Factor1 & 0.264 & 3.088 & $0.002^{* *}$ & 1.511 & \multirow{4}{*}{$\begin{array}{c}\mathrm{F}(4,152)=13.491, \\
p=0.000\end{array}$} \\
\hline Factor2 & -0.197 & -2.037 & $0.043^{*}$ & 1.93 & \\
\hline Factor3 & -0.066 & -0.627 & 0.531 & 2.26 & \\
\hline Factor4 & 0.478 & 5.284 & $0.000^{* *}$ & 1.684 & \\
\hline
\end{tabular}

$\mathrm{D}-\mathrm{W}$ value: 1.849 ${ }^{*} p<0.05,{ }^{* *} p<0.01$ 
Hypothesis $\mathrm{H} 2$ is verified. In the environment of online learning, teacher factors have a significantly positive promotion effect on individual cognitive engagement. This effect is mainly because interaction and communication among students can decrease the aloneness of online learners, as they do not simply face their computers, iPads, and other mobile terminals. In the process of online learning, experience sharing, language interaction, emotional exchange, and learning skill communication among students can all strengthen the learning enthusiasm of learners and drive learners to acquire more cognitive engagements. Particularly, various activities in the online teaching mode, such as group discussion, follow-up discussion, team cooperation in a task, and mutual peer evaluation, adapt to contemporary learners better. In the online collaborative learning process, learners are more positive in communication with other classmates, which will increase their social communication and highlight cognitive engagement more.

Hypothesis H3 is not verified. In the environment of online learning, peer factors have no significant positive promotion effect on individual cognitive engagement. Teachers have been observed to develop the evident promotion effect in online learning. However, this study reflects a basic fact: in online education, teacher factors are not as important as those in the offline face-to-face teaching mode. In online learning, teacher factors are influenced by other factors. Teachers pay more attention to online teaching resources and video representation forms. However, they ignore the objective of online education as learning and lack emotional communication with students. As a result, the support role of teachers has not been highlighted. Although learners engage in group discussions positively through encouraging feedback in online learning, few positive interaction behaviors occur between teachers and students. The encouraging feedback of teachers is in the form of individual feedback, and individual feedback mainly gives learners emotional or psychological encouragement through encouraging language. However, such encouragement influences the cognition of learners slightly. Although indicative feedback provides information related to learning content, teacher feedback brings limited inspiration to learners.

Hypothesis H4 is verified. In the environment of online learning, technological factors have a significantly positive promotion effect on individual cognitive engagement. This positive effect is mainly due to online learning having more evident advantages than offline traditional education in terms of superficial cognitive engagement. Students can concentrate on their learning screens more and strengthen their perceptual knowledge through more novel teaching expressions of online learning, such as Flash cartoons and 3D interactive answering. Currently, online learning uses a tablet PC and cloud platform learning software as technological components. Technological availability and usability are positively related to individual cognitive engagement. Therefore, increasing technological availability and usability can promote cognitive strategies and cognitive engagement to some extent. In addition, online platform resources and exercise feedback have significantly positive influences on deep cognitive engagement, such as positive and interactive strategies. This influence reflects that the platform functions of resource input and exercise feedback shall be redesigned by combining teaching scenes. 


\subsection{Mediating effect}

Table 6 shows that Hypothesis H5 is verified. In the environment of online learning, self-efficacy develops a mediating effect in the significantly positive promotion of environmental perception on individual cognitive engagement. Mediating effect analysis involves three models, namely, cognitive engagement = $1.677+0.475 *$ environmental perception, $\mathrm{M}=1.641+0.541 *$ environmental perception, and cognitive engagement $=0.981+0.246 *$ environmental perception $+0.424 *$ selfefficacy.

Table 6. Analysis of mediating effect

\begin{tabular}{|l|c|c|c|c|}
\hline \multicolumn{1}{|c|}{ Name of questions } & $\begin{array}{c}\text { Cognitive } \\
\text { engagement }\end{array}$ & Self-efficacy & $\begin{array}{c}\text { Cognitive } \\
\text { engagement }\end{array}$ & Cognitive engagement \\
\hline Constant & $\begin{array}{c}1.677^{* *} \\
(4.418)\end{array}$ & $1.641^{* *}(3.449)$ & $0.981^{* *}(2.931)$ & $1.677^{* *}(4.418)$ \\
\hline $\begin{array}{l}\text { Environmental per- } \\
\text { ception }\end{array}$ & $\begin{array}{c}0.475^{* *} \\
(4.746)\end{array}$ & $0.541^{* *}(4.311)$ & $0.246^{* *}(2.729)$ & $0.475^{* *}(4.746)$ \\
\hline Self-efficacy & - & - & $0.424^{* *}(7.786)$ & - \\
\hline Sample size & 157 & 157 & 157 & 157 \\
\hline $\mathrm{R}^{2}$ & 0.127 & 0.107 & 0.373 & 0.127 \\
\hline Regulated $\mathrm{R}^{2}$ & 0.121 & 0.101 & 0.365 & 0.121 \\
\hline F value & $\begin{array}{c}\mathrm{F}(1,155)=22.52 \\
2, p=0.000\end{array}$ & $\begin{array}{c}\mathrm{F}(1,155)=18.589, \\
p=0.000\end{array}$ & $\begin{array}{c}\mathrm{F}(2,154)=45.901, \\
p=0.000\end{array}$ & $\mathrm{~F}(1,155)=22.522, p=0.000$ \\
\hline
\end{tabular}

$\mathrm{p}<0.05,{ }^{* *} \mathrm{p}<0.01$, numbers in the brackets are t values

Self-efficacy provides some mediating effect in the positive influences of environmental perception on cognitive engagement. As a mediating variable, self-efficacy can strengthen the cognitive engagement of learners. Learners with stronger selfefficacy are more confident in exhibiting their behavior and presenting stronger tolerance to overcome difficulties in learning. Therefore, influenced by self-efficacy, learners have stronger learning motivation and ability to believe that they can accomplish online learning. In the long-term online learning environment, students experience learning burnout easily, thus resulting in reduced learning efficiency. However, learners who have high individual cognition will have stronger self-efficacy and lead them to increase their cognitive engagement.

\subsection{Difference analysis}

Table 7 shows that the variations of cognitive engagement with the duration of online learning have been analyzed through one-way analysis of variance (ANOVA). Different durations of online learning have significant differences in cognitive engagement $(p<0.05)$, thus indicating the different influences of the duration of online learning on cognitive engagement $(\mathrm{F}=4.530, p=0.005)$. Specific comparison differences have group-based mean score comparison results of evident differences. University students who have been doing online learning longer have deeper cognitive engagement. In other words, long-time use of online learning platforms can effective- 
ly promote university students' familiarization with online learning platforms. Students can switch among different learning platforms and become more familiar with the online learning skills they need to acquire, thus improving their cognitive engagements. Majors are significant in relation to cognitive engagement $(p<0.05)$. This correlation implies that different majors have varying influences on cognitive engagement.

Table 7. F-test

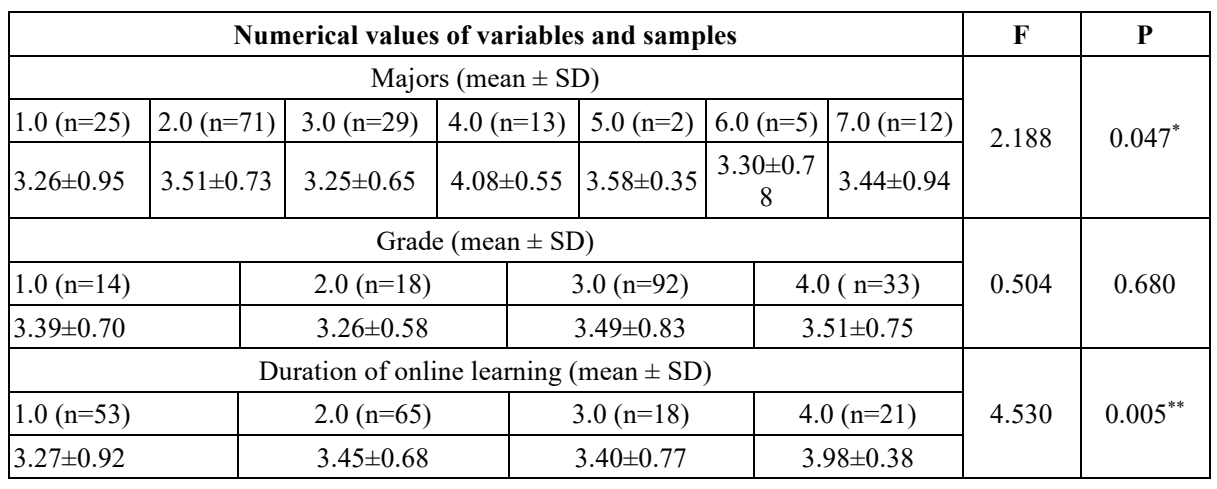

According to specific analysis, the influences of majors on cognitive engagement are significant at the 0.05 level $(\mathrm{F}=2.188, p=0.047)$. This observation demonstrates that students from different majors have significantly different cognitive engagement. The reasons can be interpreted as follows. The School of Economics and Management was established in a short time. Along with this brief history, the school has experienced a shortage of professional teachers, including International Economics and Trade, Statistics, and so on. Teachers have little experience in online teaching, and online teaching resources are inadequate. Hence, evident differences in cognitive engagement among majors have been recorded.

Table 8 demonstrates that no significant gender difference exists in cognitive engagement. However, males have slightly higher cognitive engagement than females. This outcome is consistent with most research conclusions. Moreover, this higher engagement is mainly due to males having better regulation over their learning rhythms, better control and scheduling plans, and higher proactivity in academic performances than females. As such, they can regulate emotions and engage in learning promptly.

Table 8. T-test results

\begin{tabular}{|c|c|c|c|c|}
\hline \multirow{3}{*}{ Cognitive engagement } & \multicolumn{2}{|c|}{ Gender (mean \pm SD) } & \multirow{2}{*}{ T } & \multirow{2}{*}{ P } \\
\cline { 2 - 5 } & Males $(\mathrm{n}=86)$ & Females $(\mathrm{n}=71)$ & & \\
\cline { 2 - 5 } & $3.54 \pm 0.76$ & $3.36 \pm 0.79$ & 1.466 & 0.145 \\
\hline
\end{tabular}


Paper-Influences of Environmental Perception on Individual Cognitive Engagement in Online Learning...

\section{Conclusions}

Technologies like big data, 5G technology, and AI accelerate the integration and coexistence of the education industry and other industries. The applications of technology in education ecology promote changes in the education concept and innovations of teaching mode. Through online learning, learners shift from the previous group learning environment into a separated individual learning environment. Such social isolation easily causes low cognitive engagement among learners. Hence this study proposes research hypotheses regarding the influences of the environmental perception of online learning (including students' self-factors, teacher factors, peer factors, and technological factors) on individual cognitive engagement (deep engagement and superficial engagement). The mediating effect of the influences of selfefficacy on individual cognitive engagement under the online learning model was estimated. The following conclusions can be drawn: the questionnaire has very good reliability and validity. In the online learning environment, students' self-factors, peer factors, and technological factors can promote individual cognitive engagement significantly, and self-efficacy develops a mediating effect in the significantly positive promotion of environmental perception on individual cognitive engagement. Cognitive engagement changes with the duration of online learning. Moreover, the influences of majors on cognitive engagement differ significantly. Thus, future research calls for in-depth studies on capturing individual, environmental, and behavioral dynamic changes in scenarios and disclosing the variation laws of individual cognitive engagement with specific environmental factors.

\section{$6 \quad$ References}

[1] Bandura, A. (1989). Human agency in social cognitive theory. American Psychologist, 44(9), 1175-1184. https://doi.org/10.1037/0003-066X.44.9.1175

[2] Appleton, J. J., Christenson, S. L., Kim, D., \& Reschly, A. L. (2006). Measuring cognitive and psychological engagement: Validation of the student engagement instrument. Journal of School Psychology, 44(5), 427-445. https://doi.org/10.1016/j.jsp.2006.04.002

[3] Smit, K., de Brabander, C. J., Boekaerts, M., \& Martens, R. L. (2017). The self-regulation of motivation: Motivational strategies as mediator between motivational beliefs and engagement for learning. International Journal of Educational Research, 82, 124-134. https:// doi.org/10.1016/j.ijer.2017.01.006

[4] Chi, M. T., Adams, J., Bogusch, E. B., Bruchok, C., Kang, S., Lancaster, M., Li, N., McEldoon, K. L., Stump, G. S., Wylie, R., Xu, D., \& Yaghmourian, D. L. (2018). Translating the ICAP theory of cognitive engagement into practice. Cognitive Science, 42(6), 1777-1832. https://doi.org/10.1111/cogs.12626

[5] Miltiadou, M., \& Savenye, W. C. (2003). Applying social cognitive constructs of motivation to enhance student success in online distance education. AACE Journal, 11(1), 78-95. https://doi.org/10.4324/9780203095737

[6] Songkram, N., Khlaisang, J., Puthaseranee, B., \& Likhitdamrongkiat, M. (2015). Elearning system to enhance cognitive skills for learners in higher education. ProcediaSocial and Behavioral Sciences, 174, 667-673. http://doi.org/10.1016/j.sbspro.2015.01.599 
Paper-Influences of Environmental Perception on Individual Cognitive Engagement in Online Learning...

[7] Yi, X. (2021). Research on the Cognitive Input Evaluation Model of MOOC Online Learning from the Perspective of Learning Analysis. In 2021 International Symposium on Educational Technology (ISET) (pp. 211-215). IEEE. https://doi.org/10.1109/iset52350.2021.0 $\underline{0051}$

[8] Lamb, R. L., Vallett, D. B., Akmal, T., \& Baldwin, K. (2014). A computational modeling of student cognitive processes in science education. Computers \& Education, 79, 116-125. http://doi.org/10.1016/j.compedu.2014.07.014

[9] Rotgans, J. I., \& Schmidt, H. G. (2011). Cognitive engagement in the problem-based learning classroom. Advances in health sciences education, 16(4), 465-479. http://doi.org/10.10 07/s10459-011-9272-9

[10] Helme, S., \& Clarke, D. (2001). Identifying cognitive engagement in the mathematics classroom. Mathematics Education Research Journal, 13(2), 133-153. http://doi.org/10.100 $\underline{7 / \mathrm{BF} 03217103}$

[11] Archambault, I., Janosz, M., Morizot, J., \& Pagani, L. (2009). Adolescent behavioral, affective, and cognitive engagement in school: Relationship to dropout. Journal of School Health, 79(9), 408-415. http://doi.org/10.1111/j.1746-1561.2009.00428.x

[12] Metallidou, P., \& Vlachou, A. (2007). Motivational beliefs, cognitive engagement, and achievement in language and mathematics in elementary school children. International Journal of Psychology, 42(1), 2-15. http://doi.org/10.1080/00207590500411179

[13] Li, Y., \& Lerner, R. M. (2013). Interrelations of behavioral, emotional, and cognitive school engagement in high school students. Journal of Youth and Adolescence, 42(1), 2032. http://doi.org/10.1007/s10964-012-9857-5

[14] Walker, C. O., Greene, B. A., \& Mansell, R. A. (2006). Identification with academics, intrinsic/extrinsic motivation, and self-efficacy as predictors of cognitive engagement. Learning and Individual Differences, 16(1), 1-12. http://doi.org/10.1016/j.lindif.2005.06.0 $\underline{04}$

[15] Archambault, I., Janosz, M., \& Chouinard, R. (2012). Teacher beliefs as predictors of adolescents' cognitive engagement and achievement in mathematics. The Journal of Educational Research, 105(5), 319-328. http://doi.org/10.1080/00220671.2011.629694

[16] Greene, B. A. (2015). Measuring cognitive engagement with self-report scales: Reflections from over 20 years of research. Educational Psychologist, 50(1), 14-30. http://doi.org/10.1 080/00461520.2014.989230

[17] Greene, B. A., Miller, R. B., Crowson, H. M., Duke, B. L., \& Akey, K. L. (2004). Predicting high school students' cognitive engagement and achievement: Contributions of classroom perceptions and motivation. Contemporary Educational Psychology, 29(4), 462-482. http://doi.org/10.1016/j.cedpsych.2004.01.006

\section{Authors}

Lei Liu, Ph.D., is a lecturer at the School of Economics, Wuhan Textile University. His research interests focus on industrial economics (email: dl_ray@126.com).

Zhaolin Duan, Master's degree candidate, in the School of Law, Humanities and Sociology, Wuhan University of Technology. Her research interests focus on emergency management.

Article submitted 2021-12-31. Resubmitted 2022-01-28. Final acceptance 2022-02-07. Final version published as submitted by the authors. 